\title{
Effectiveness of Imazodan for Treatment of Chronic Congestive Heart Failure
}

\author{
A. David Goldberg, MD, John Nicklas, MD, and Sidney Goldstein, MD, \\ for the Imazodan Research Group*
}

\begin{abstract}
A 12-week, multicenter, double-blind, randomized, placebo-controlled trial of imazodan, a type III phosphodiesterase inhibitor, was conducted in 147 patients with congestive heart failure to determine clinical efficacy and safety. Patients were randomized to placebo or 2,5 or $10 \mathrm{mg}$ of imazodan administered twice daily. Patients were maintained on their standard therapy including diuretics, digoxin and an angiotensinconverting enzyme inhibitor. The mean ejection fraction was $23 \pm 10 \%$. Exercise time increased from baseline in all 4 groups. There was no significant difference observed between the placebo group and any of the treated groups with regard to exercise time, ejection fraction, frequency of ventricular premature complexes or ventricular tachycardia. When analyzed by intent to treat, the placebo mortality was $7 \%$ (3 of 44) and the imazodan mortality was $8 \%(8$ of 103$)(p=$ not significant). This study failed to demonstrate that imazodan provided any benefit in exercise performance when compared with placebo.
\end{abstract}

(Am J Cardiol 1991;68:631-636)

From the Division of Cardiovascular Medicine, Henry Ford Heart and Vascular Institute, Detroit, Michigan, and the Division of Cardiovascular Medicine, University of Michigan School of Medicine, Ann Arbor, Michigan. This study was supported by a grant from Parke-Davis Pharmaceutical Research Division, Warner Lambert Company, Ann Arbor, Michigan. Manuscript received March 14, 1991; revised manuscript received and accepted May 3, 1991.

Address for reprints: A. David Goldberg, MD, Division of Cardiovascular Medicine, Henry Ford Hospital, 2799 W Grand Boulevard, Detroit, Michigan 48202.

*See Appendix for list of investigators.
$\mathrm{T}$ he optimal treatment of congestive heart failure (CHF) remains a major clinical issue despite treatment with digitalis and diuretics. The use of vasodilators, ${ }^{1}$ especially the angiotensin-converting enzyme inhibitors, ${ }^{2,3}$ have improved both symptoms and prognosis. Nevertheless, the mortality of patients with advanced CHF remains high and many patients continue to be severely symptomatic despite medical therapy. Type III phosphodiesterase inhibitors may provide an alternative or additional treatment for CHF. These agents have demonstrated hemodynamic efficacy in the acute setting. ${ }^{4-10}$ However, long-term trials studying the effect on exercise performance have generally been disappointing. ${ }^{11-16}$

Imazodan hydrochloride (CI 914), a selective inhibitor of type III phosphodiesterase, blocks the degradation of cyclic adenosine monophosphate leading to increased intracellular concentrations, thereby increasing myocardial contractility. Imazodan also acts as a peripheral vasodilator in a variety of animal models. ${ }^{17}$ Initial human studies ${ }^{8}$ indicated that after intravenous or oral administration of imazodan, cardiac output increases and pulmonary capillary pressure and systemic vascular resistance decrease. Pharmacokinetic studies suggested a half-life of 15 to 25 hours, allowing twicedaily administration.

The primary objective of this study was to determine whether, during a 12-week period, 1 or more dosing regimens of orally administered imazodan were more effective than placebo at increasing exercise time on a treadmill in patients with moderate to scvere chronic $\mathrm{CHF}$.

\section{METHODS}

Patient population: The study was designed to enroll 160 patients. Recruitment was discontinued after 147 patients were randomized after an analysis of the initial 80 patients indicated that a positive effect of the drug was unlikely to be achieved. Each patient was required to provide written informed consent, be aged $>18$ and $<75$ years and have chronic CHF in which dyspnea or fatigue limited their exercise. Patients were allowed to continue receiving antiarrhythmic agents except for disopyramide. Short-acting nitrates and constant doses of digitalis and angiotensin-converting enzyme inhibitors were permitted. Diuretic doses could be decreased, but 


\begin{tabular}{|c|c|c|c|c|c|c|}
\hline & $\begin{array}{l}\text { No. of Pts. } \\
(n=147)\end{array}$ & $\begin{array}{l}\text { Placebo } \\
(n=44)\end{array}$ & $\begin{array}{l}\text { Imazodan } \\
2 \mathrm{mg} \text { BID } \\
(\mathrm{n}=34)\end{array}$ & $\begin{array}{l}\text { Imazodan } \\
5 \mathrm{mg} \text { BID } \\
(\mathrm{n}=37)\end{array}$ & $\begin{array}{l}\text { Imazodan } \\
10 \mathrm{mg} \mathrm{BID} \\
(n=32)\end{array}$ & $\begin{array}{l}\mathrm{p} \\
\text { Value }\end{array}$ \\
\hline Men & $128(87)$ & $39(89)$ & $32(94)$ & $30(81)$ & $27(84)$ & 0.39 \\
\hline Age & $59 \pm 9.7$ & $57.5 \pm 9.8$ & $59.6 \pm 12.2$ & $60.9 \pm 7.2$ & $58.3 \pm 9.2$ & 0.43 \\
\hline NYHA & & & & & & 0.28 \\
\hline Class III & $72(49)$ & $22(50)$ & $12(35)$ & $18(49)$ & $20(63)$ & \\
\hline Class IV & $7(5)$ & $2(5)$ & $1(3)$ & $3(8)$ & $1(3)$ & \\
\hline Etiology & & & & & & 0.19 \\
\hline CAD & $78(53)$ & $20(45)$ & $23(68)$ & $20(54)$ & $15(47)$ & \\
\hline SH & $16(11)$ & $7(16)$ & $0(0)$ & $5(14)$ & $4(13)$ & \\
\hline IDC & $35(24)$ & $12(27)$ & $7(21)$ & $10(27)$ & $6(19)$ & \\
\hline Other & $18(12)$ & $5(11)$ & $4(12)$ & $2(3)$ & $7(22)$ & \\
\hline Exercise time(s) & $506 \pm 145$ & $529 \pm 152$ & $526 \pm 128$ & $462 \pm 160$ & $502 \pm 127$ & 0.18 \\
\hline Ejection fraction (\%) & $23 \pm 10$ & $24 \pm 11$ & $22 \pm 7$ & $20 \pm 9$ & $25 \pm 11$ & 0.18 \\
\hline \multicolumn{7}{|l|}{ Holter } \\
\hline VPCs/hour & $153 \pm 253$ & $189 \pm 270$ & $170 \pm 313$ & $106 \pm 185$ & $140 \pm 228$ & 0.52 \\
\hline 24-hour HR & $86 \pm 12$ & $88 \pm 11$ & $85 \pm 11$ & $84 \pm 13$ & $85 \pm 12$ & 0.36 \\
\hline$V$ runs/day & $2.3 \pm 9.2$ & $4.7 \pm 14.1$ & $1 \pm 2.5$ & $2.2 \pm 9.0$ & $0.5 \pm 0.9$ & 0.19 \\
\hline \multicolumn{7}{|l|}{$\begin{array}{l}\text { Concurrent } \\
\text { medications }\end{array}$} \\
\hline Digitalis & $124(84)$ & $38(86)$ & $27(79)$ & $32(86)$ & $27(84)$ & 0.83 \\
\hline $\begin{array}{l}\text { Lasix dose } \\
\text { mg/day }\end{array}$ & $91 \pm 67$ & $98 \pm 73$ & $86 \pm 68$ & $91 \pm 61$ & $87 \pm 65$ & 0.86 \\
\hline ACE inhibitors & $81(55)$ & $25(57)$ & $20(59)$ & $20(54)$ & $16(50)$ & 0.90 \\
\hline
\end{tabular}

not increased from that taken during the placebo baseline phase. Women with child-bearing potential were excluded.

Study design: This study was a double-blind, parallel-group comparison of imazodan therapy (2,5 and 10 $\mathrm{mg}$, administered twice daily) with placebo in patients with chronic CHF. The study began with a 2- to 4week, single-blind, placebo phase during which routine laboratory and cardiac studies were performed.

During the baseline phase, treadmill exercise tests were performed each week using the Naughton protocol modified by Weber et al. ${ }^{18}$ Before randomization, 2 consecutive symptom-limited maximal exercise tolerance tests had to be performed between 4 and 12 minutes and had to be reproducible to within 10\%. Patients were then randomly assigned to 1 of the 4 treatment groups and were evaluated every week for 12 weeks. Exercise tests were performed at baseline and at weeks 4,8 and 12. Ejection fraction was measured by gated radionuclide angiography at baseline and 12 weeks. Twenty-four-hour Holter monitorings were performed at baseline and weeks 1, 4 and 10, and were analyzed at a central site (Cardiodata Inc.). Each tape was analyzed for average 24-hour heart rate, ventricular premature complexes per hour and ventricular runs $(>4$ beats at a rate $>100$ beats $/ \mathrm{min} /$ day).

Patients who withdrew from the study because of lack of efficacy before completing the 12 weeks were eligible to enter an open-label treatment program in which imazodan could be initiated or increased for symptomatic relief of $\mathrm{CHF}$.

Differences in baseline variables between treatment groups were analyzed by chi-square analysis for discontinuous variable and analysis of variance. Changes in exercise times, ejection fraction, 24-hour heart rate, frequency of ventricular premature complexes and ventricular runs were analyzed by 1 factor analysis of variance using treatment group as the independent factor. A p value $<0.05$ was considered significant. Definitions from the Cardiac Arrhythmia Pilot Study ${ }^{19}$ were used for determining proarrhythmia.

Results were analyzed by intent to treat and also by end point analysis of the last laboratory determinant before the time the double-blind phase was broken because of increased symptoms or death. For the doubleblind phase and through 84 days, the relation of the treatment group to survival was examined by estimating survival curves for each treatment using the product-limit method of Kaplan and Mcier. The equality of the 4 survival distributions was tested by the log rank (Mantel-Cox) statistic.

Data collection was performed by Parke-Davis Pharmaceutical Research Division. Data were analyzed at the Division of Cardiology, Henry Ford Heart and Vascular Institute with the assistance of the Department of Biostatistics, Henry Ford Hospital.

A safety committee (see Appendix), established before the study initiation, was charged with reviewing 
the safety data. The members of the committee were unaware of patient characteristics and had access to the dose of drug each patient was receiving, description of deaths and other adverse events, 24-hour Holter monitor results and clinical laboratory findings.

\section{RESULTS}

The baseline characteristics of the 147 patients who entered the study are listed in Table I. The treatment groups were similar with respect to all baseline demographic variables (Table I).

Exercise response: Increases in exercise tolerance were seen in all groups compared with baseline (Figure 1). There was no significant difference between the 4 treatment groups in the change in exercise time from baseline to weeks 4,8 and 12 (Table II). There was no significant change in ejection fraction between the treatment groups during the study period (Table III).

Of the 146 patients who werc classificd by New York Heart Association class during both baseline and double-blind phases, $122(84 \%)$ remained in the same class, 12 patients ( $8 \%$ ) improved, and 12 were worse. There was no significant difference in class change between the 4 treatment groups $(p=0.7)$.

Arrhythmias: In the imazodan 5- and 10-mg groups, a significant increase in 24-hour average heart rates was observed at 1,4 and 10 weeks (Table IV).

No significant change occurred in the average frequency of ventricular premature beats per hour (Table V) or runs of ventricular ectopic beats compared with baseline in any treatment group at 1, 4 or 10 weeks. According to the Cardiac Arrhythmia Pilot Study ${ }^{19}$ definitions there were 15 patients who had proarrhyth-

\begin{tabular}{|c|c|c|c|c|c|}
\hline $\begin{array}{l}\text { Visit } \\
\text { (week) }\end{array}$ & Placebo & $\begin{array}{l}\text { Imazodan } \\
\text { (2 mg BID) }\end{array}$ & $\begin{array}{l}\text { Imazodan } \\
\text { (5 mg BID) }\end{array}$ & $\begin{array}{l}\text { Imazodan } \\
\text { (10 mg BID) }\end{array}$ & $\begin{array}{l}p \\
\text { Value }\end{array}$ \\
\hline 4 & $24 \pm 108$ & $83 \pm 79$ & $75 \pm 121$ & $32 \pm 123$ & 0.08 \\
\hline 8 & $45 \pm 114$ & $65 \pm 103$ & $67 \pm 127$ & $0 \pm 127$ & 0.16 \\
\hline 12 & $48 \pm 158$ & $83 \pm 129$ & $99 \pm 128$ & $52 \pm 161$ & 0.58 \\
\hline
\end{tabular}

\begin{tabular}{|lcccc|}
\hline \multicolumn{5}{|c|}{ TABLE III Change in Ejection Fraction (\%) } \\
\hline & Placebo & \multicolumn{1}{c|}{$\begin{array}{l}\text { Imazodan } \\
\text { (2 mg BID) }\end{array}$} & $\begin{array}{l}\text { Imazodan } \\
\text { (5 mg BID) }\end{array}$ & $\begin{array}{l}\text { Imazodan } \\
\text { (10 mg BID) }\end{array}$ \\
\hline No. of pts. & 31 & 29 & 28 & 23 \\
Baseline (\%) & $26 \pm 11$ & $21 \pm 8$ & $22 \pm 9$ & $25 \pm 12$ \\
End point (\%) & $24 \pm 11$ & $22 \pm 9$ & $22 \pm 12$ & $25 \pm 14$ \\
Difference (\%) & $-2.4 \pm 9.9$ & $0 \pm 6.5$ & $0.25 \pm 6.9$ & $-0.09 \pm 6.7$ \\
p Value & 0.18 & 1 & 0.85 & 0.95 \\
\hline
\end{tabular}

\begin{tabular}{|rrrlll|}
\hline \multicolumn{7}{|c|}{ TABLE IV Change in Average 24-Hour Heart Rate } \\
\hline \multicolumn{7}{|c|}{ Week Placebo } & Imazodan & Imazodan & Imazodan & $p$ \\
& (2 mg BID) & (5 mg BID) & (10 mg BID) & Value \\
\hline 1 & $1.5 \pm 4.7$ & $0.5 \pm 6.0$ & $4.8 \pm 7.4$ & $4.8 \pm 6.0$ & $<0.005$ \\
4 & $-0.5 \pm 6.6$ & $2.0 \pm 9.0$ & $4.3 \pm 8.8$ & $6.4 \pm 7.0$ & 0.005 \\
10 & $-2.2 \pm 6.6$ & $-0.2 \pm 6.7$ & $4.3 \pm 10.6$ & $6.0 \pm 10.3$ & $<0.005$ \\
\hline
\end{tabular}

mia on the week 1 Holter. These were distributed evenly through the 4 treatment groups.

Safety: Patient withdrawals during the double-blind phase are listed in Table VI. There was a tendency for greater withdrawal from the placebo group for lack of efficacy than from the imazodan treatment groups. No adverse effects related to imazodan were reported. Investigators reported 7 patients with severe adverse effects requiring withdrawal from the study: These included stomach irritation, resuscitated sudden death,
FICURE 1. Change in exercise time during the follow-up period in the groups taking placebo and $2.5,5$ or $10 \mathrm{mg}$ of imazodan twice daily. * $p<0.05$ change from baseline.

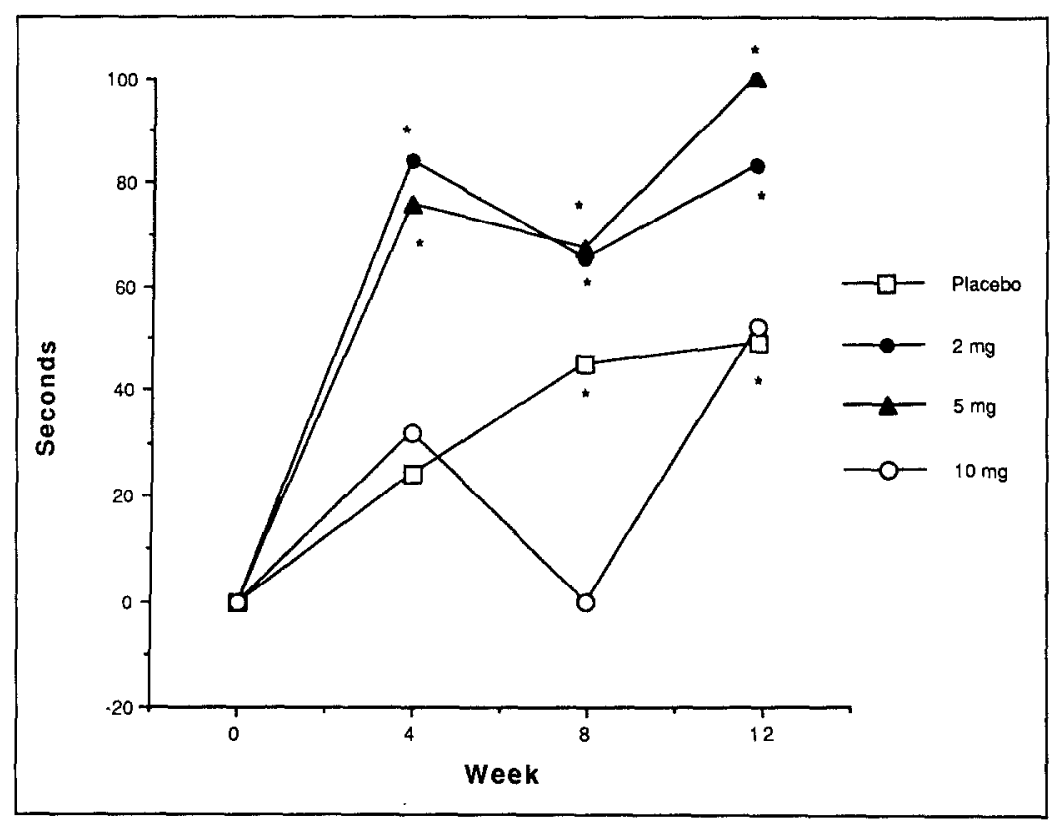




\begin{tabular}{|llllll|}
\hline TABLE V Frequency of Ventricular Premature Complexes Per Hour & & & \\
\hline & & Imazodan & Imazodan & Imazodan & $p$ \\
& Placebo & $(2 \mathrm{mg} \mathrm{BID})$ & (5 mg BID $)$ & (10 mg BID) & Value \\
\hline Bascline & $189 \pm 270$ & $170 \pm 313$ & $106 \pm 185$ & $140 \pm 228$ & 0.52 \\
Week 1 & $190 \pm 237$ & $188 \pm 327$ & $143 \pm 179$ & $109 \pm 158$ & 0.49 \\
Week 4 & $221 \pm 287$ & $189 \pm 373$ & $163 \pm 172$ & $98 \pm 114$ & 0.33 \\
Week 10 & $197 \pm 266$ & $167 \pm 339$ & $163 \pm 253$ & $122 \pm 172$ & 0.82 \\
\hline
\end{tabular}

\begin{tabular}{|c|c|c|c|c|}
\hline & Placebo & $\begin{array}{l}\text { Imazodan } \\
\text { (2 mg BID) }\end{array}$ & $\begin{array}{l}\text { Imazodan } \\
\text { (5 mg BID) }\end{array}$ & $\begin{array}{l}\text { Imazodan } \\
\text { (10 mg BID) }\end{array}$ \\
\hline Death & 0 & 0 & 4 & 3 \\
\hline Adverse experience & 2 & 0 & 3 & 2 \\
\hline Lack of efficacy & 3 & 1 & 0 & 0 \\
\hline Concurrent illness & 2 & 2 & 0 & 1 \\
\hline Other withdrawal & 6 & 2 & 6 & 4 \\
\hline Completed week 12 & 32 & 30 & 26 & 22 \\
\hline
\end{tabular}

lightheadedness and headache, nausea, anorexia and weakness, postural dizziness and hypotension, worsening $\mathrm{CHF}$ and ventricular arrhythmias.

There were 13 patients with ventricular arrhythmias reported as adverse events by the investigators. Of these, 6 were receiving placebo, 1 was receiving imazodan $2 \mathrm{mg}, 4$ imazodan $5 \mathrm{mg}$ and 2 imazodan $10 \mathrm{mg}$ twice daily.

By intent-to-treat analysis the mortality in the placebo group was $7 \%$ ( 3 of 44 ) and in the imazodan groups $8 \%$ ( 8 of 103) ( $p=$ not significant). During the double-blind phase of the study there were 7 deaths, 5 of them sudden. Four deaths occurred in the imazodan $5 \mathrm{mg}$ and 3 in the imazodan $10 \mathrm{mg}$ groups. There were 4 additional deaths during the 12-week period in patients who were withdrawn from the double-blind phase. Three were originally in the placebo group and at the time of death 1 of these was taking imazodan 5 $\mathrm{mg}$ and another $15 \mathrm{mg}$ twice daily. One was initially in the imazodan 10-mg group, but was withdrawn while hospitalized for $\mathrm{CHF}$ and died 11 days later. Patients who died had lower ejection fraction (14 vs $23 \%$, p $<0.02$ ), lower baseline exercise times ( 379 vs 512 seconds, $\mathrm{p}<0.02$ ), and were less likely to be taking an angiotensin-converting enzyme inhibitor (14 vs $57 \%$, p $<0.03)$.

\section{DISCUSSION}

This study examined the efficacy and safety of a new type III phosphodiesterase inhibitor over a range of doses. During the 3 months of follow-up, exercise performance and ejection fraction did not significantly improve when compared with the effect of the placebo.
The drug appeared to be well tolerated. Frequency of ventricular ectopy did not increase, although there was the increase in heart rate seen in the patients taking the larger doses of imazodan. The cause of this chronotropic response has not been previously described and warrants further investigation.

Previous studies with imazodan (CI-914), ${ }^{8}$ its anla$\log$ CI- $930^{9}$ and other phosphodiesterase inhibitors indicatc that intravcnous and oral therapy results in an increase in cardiac output and a reduction in peripheral vascular resistance. $\Lambda$ lthough most studies suggest that these drugs have a positive inotropic action, it is difficult, in humans, to separate the effect on contractility from the direct vasodilatation. Patients treated with $\mathrm{CI}$ $930^{9}$ were observed to have an increase in frequency of ventricular ectopy which was not found in this study.

Other phosphodiesterase inhibitors have heen evaluated for the treatment of chronic CHF. Amrinone ${ }^{4}$ and milrinone, ${ }^{5}$ both bipyridine derivatives, have significant inotropic and vasodilator effects in the acute setting. The effects of long-term amrinone therapy on exercise performance have been disappointing. Massie et al ${ }^{12}$ compared amrinone with placebo in 99 patients with chronic $\mathrm{CHF}$ and found no difference in exercise ability over a 12-week period. A multicenter placebo-controlled comparison of milrinone with digoxin ${ }^{13}$ found an improvement in exercise performance in patients given either milrinone or digoxin when compared with placebo, but no additional benefit to the combination of milrinone and digoxin.

Enoximone ${ }^{6}$ and piroximone, ${ }^{7}$ like imazodan, are imidazol derivatives with acute hemodynamic effects similar to amrinone and milrinone. Whereas there have been numerous acute and chronic studies of enoximone ${ }^{20}$ in patients with heart failure, few have been controlled. Uretsky et al, ${ }^{16}$ in a study of 102 patients with chronic $\mathrm{CHF}$, found no improvement in exercise capacity or symptons compared with placebo.

The design of this study would have permitted an analysis of mortality over 12 weeks although the power was not calculated for studying survival. However, patients who discontinued the double-blind study early were allowed to begin the open-label phase immediately. This resulted in the administration of imazodan, before 84 days, to some patients randomized to placebo. 
By intent-to-treat analysis for the 84 days, there was no significant difference in mortality between the placebo group (7\%) and those treated with imazodan (8\%). The fact that all the deaths that occurred during the double-blind phase were in patients taking large doses of imazodan is disturbing. The effect of phosphodiesterase inhibitors on survival has not been studied in a rigorous manner. Most of the initial hemodynamic studies were conducted in patients with severe heart failure in whom the expected mortality was high. In the few placebo-controlled studies, ${ }^{12,13,16}$ as in this study, there has been a disturbing and consistent trend toward increased mortality in the treatment group. Colucci ${ }^{21}$ reviewed 571 patients enrolled in 3 placebo-controlled studies of milrinonc and concluded that there was no evidence for an adverse effect of that drug on mortality. In the largest of these studies, however, there was a trend $(p=$ 0.08 ) toward reduced survival in the milrinone-treated group. The investigators attributed this to a baseline imbalance in ejection fraction which suggested that milrinone was given to a sicker population. After post hoc adjustment of this covariant, the trend toward increased mortality was no longer present. Recently, a mortality study of milrinone in patients with class III and IV heart failure was prematurely terminated because of increased mortality in the milrinone-treated group (Schwartz R, personal communication, Sterling Winthrop, Inc.). Uretsky et al ${ }^{16}$ found a higher mortality in enoximone-treated patients than in a placebotreated group. This increase in mortality was significant when the study was analyzed by double-blind ( $p$ $<0.05)$ or intention-to-treat $(\mathrm{p}<0.05)$ analyses. In our study, the increased mortality rate was observed in the large dose ranges, suggesting a dose effect.

\section{REFERENCES}

1. Cohn JN, Archibald DG, Ziesche S, Franciosa JA, Harston WE, Tristani FE, Dunkman WB, Jacobs W, Francis GS, Flohr KH. Effect of vasodilator therapy on mortality in chronic congestive heart failure. Results of a Veterans Administration Cooperative Study. $N$ Engl $J$ Med 1986;314:1547-1552.

2. Captopril-Digoxin Multicenter Research Group. Comparative effects of captopril and digoxin in patients with mild to moderate heart failure. JAMA 1988;259:539-544.

3. CONSENSUS Study Trial Group. Effects of enalopril on mortality in severe heart failure. Results of the CONSENSUS Trial (Cooperative North American Enalopril Survival Study). N Engl J Med 1987;316:1429-1435.

4. Benotti JR, Grossman W, Braunwald E, Davolos DD, Alousi AA. Hemodynamic assessment of amrinone. N Engl J Med 1978;299:1373-1377.

5. Baim DS, McDowell AV, Cherniles J, Monrad ES, Parker JA, Edelson J, Braunwald E, Grossman W. Evaluation of a new bipyridine inotropic agent - milrinone - in patients with severe congestive heart failure. $N$ Engl J Med 1983;309:748-756.

6. Crawford MH, Richards KL, Sodums MT, Kennedy GT. Positive inotropic and vasodilator effects of MDL 17,403 in patients with reduced left ventricular performance. Am J Cardiol 1984;53:1051-1053.

7. Petcin M, Levine TB, Cohn JN. I Iemodynamic effects of a tlew inutropic agent, piroximone (MDL 19205), in patients with chronic heart failure. $J$ Am Coll
Cardiol 1984;4:364-371.

8. Jafri SM, Burlew BS, Goldberg AD, Rogers A, Goldstein S. Hemodynamic effects of a new type III phosphodiesterase inhibitor (CI-914) for congestivc heart failure. Am J Cardiol 1986;57:254-259.

9. Jafri SM, Burlew BS, Goldberg AD, Olsen S, Froelich JW, Goldstein S. Henodynamic, pharmacokintic and clinical response to CI-930 in congestive heart failure due to ischemic or dilated cardiomyopathy. Am J Cardiol 1987;59:1126-1130.

10. Maskin CS, Sinoway L, Chadwick B, Sonnenblick EH, Lelemtel TH. Sustained hemodynamic and clinical effects of a new cardiotonic agent, WIN 47203, in patients with severe congestive heart failure. Circulation 1983;67:1065 1070 .

11. Packer M, Medina N, Yushak M. Hemodynamic and clinical limitations of long-term inotropic therapy with amrinone in patients with severe chronic heart failure. Circulation 1984;70:1038-1047.

12. Massie B, Bourassa M, DiBianco R, Hess M, Konstam M, Likoff M, Packer $M$, for the Amrinone Multicenter Trial Group. Long-term oral administration of amrinone for congestive heart failure: lack of efficacy in a multicenter controlled trial. Circulation 1985;71:963-971.

13. DiBianco R, Shabetai R, Kostuk W, Moran J, Schlant RC, Wright R, for the Milrinone Multicenter Trial Group. A comparison of oral milrinone, digoxin and their combination in the treatment of patients with chronic heart failure. $N$ Engl $J$ Med 1989;320:677-683.

14. Shah PK, Amin DK, Hulse S, Shellock F, Swan HJC. Inotropic therapy for refractory congestive heart failure with oral fenoximone (MDL-17,043): poor long-tcrm rcsults despite early hemodynamic and clinical improvement. Circulation 1985;71:326-331.

15. Petein M, Levine TB, Cohn JN. Persistent hemodynamic effects without long-term clinical benefits in response to oral piroximone (MDL 19,205) in patients with congestive heart failure. Circulation 1986;73(suppl III):III-230-III236.

16. Uretsky BF, Jessup M, Konstam MA, Dec GW, Leier CV, Benotti J, Murali $\mathrm{S}$, Hermann HC, Sandberg JA for the Enoximone Multicenter Trial Group. Multicenter trial of oral enoximone in patients with moderate to moderately severe congestive heart failure. Circulation 1990;82:774-780.

17. Weishaar RE, Quade M, Schenden JA, Boyd DK, Evans DB. Studies aimed at elucidating the action of CI-914, a new cardiotonic. Eur $J$ Pharmacol 1985;1 19:205-215.

18. Weber KT, Kinasewitz GT, West JS, Janicki JS, Reichek N, Fishman AP. Long-term vasodilator therapy with trimazosinin chronic cardiac failure. $N$ Engl J Med 1980;303:242-250.

19. The Cardiac Arrhythmia Pilot Study. Am J Cardiol 1986;57:91-95.

20. Hond WR. Controlled and uncontrolled studies of phosphodiesterase III inhibitors in contemporary cardiovascular medicine. Am J Cardiol 1989; 63:46A-53A

21. Colucci WS. Antagonist's viewpoint. $J$ Am Coll Cardiol 1988;12:566-569.

\section{APPENDIX}

List of participating investigators: Albert Einstein College of Medicine, Bronx, NY: T.H. LeJemtel, MD; Austin Diagnostic Clinic, Austin, TX: M. Rotman, MD; Central Cardiology Medical Clinic, Bakersfield, CA: T.A. Don Michael, MD, P.F.N. Perera, MD, T. Ishimori, MD, L. Heller, MD; Hahnemann Medical College, Philadelphia, PA: M. Likoff, MD; Henry Ford Hospital, Detroit, MI: A.D. Goldberg, MD; LA County/USC Medical Center, Los Angeles, CA: P.A.N. Chandraratna, MD; Michael Reese Hospital \& Medical Center, Chicago, IL: K.T. Weber, MD; Millard Fillmore Hospital, Buffalo, NY: A. Goldfarb, MD, R.W. Thomas, Pharm.D., A.B. Celnarowski, Pharm.D., J.J. Schentag, Pharm.D.; Sinai Hospital of Detroit, Detroit, MI: H.J. Willens, MD, R.D. Blevins, Pharm.D., M.J. Goldberg, MD; San Francisco General Hospital, San 
Francisco, CA: R.M. Morelli, MD; Southern Nevada Memorial Hospital, Las Vegas, NV: A.M. Marlon, MD; University of Pittsburgh/Presbyterian University Hospital, Pittsburgh, PA: B.F. Uretsky, MD; University of Michigan, Ann Arbor, MI: J. Nicklas, MD; Veterans Administration Medical Center, Bay Pines, FL: J.W. Linhart, MD, J.G. Finn, MD; Veterans Administration Medical Center, Washington, DC: S.N. Singh, MD, J.S. Gottdiener, MD; West Pennsylvania Cardiology Associates, Pittsburgh, PA: F. Porkolab, MD, R.L. Heppner, MD, B.L. Alpert, MD.
Names and addresses of safety committee members: Edward A. Carr, Jr., MD, Department of Pharmacology \& Therapeutics, School of Medicine, 127 Farber Hall, S.U.N.Y. at Buffalo, Buffalo, NY 14214; Prof. Paul Meier, Department of Statistics, 5734 University Ave., University of Chicago, Chicago, IL 60637; Henry Swain, MD, Department of Pharmacology, M6322 Medical Science I, University of Michigan, Ann Arbor, MI 48109; Park W. Willis, III, MD, B-220 Life Sciences Bldg., Michigan State University, East Lansing, MI 48824. 